to another, that an entirely different condition may, of course, present itself in 1918. We mean that the worms may not be so plentiful for some reason and if this should prove true, it will be difficult to obtain very much information.

From our observations this summer (1917) we firmly believe that the nematodes accomplished an immense reduction in the number of grasshoppers near Dummerston Station, Vermont. This worm, if its life-history is investigated, might offer possibilities for introduction into regions where it does not occur and where grasshoppers are a pest. For this reason, and because we were unable to find any records of such a high degree of parasitism, we thought it best to present these preliminary observations.

\title{
THE PULSATILE VESSELS IN THE LEGS OF APHIDIDÆ.
}

By Chas. H. Richardson,

College of Physicians and Surgeons, Columbia University, New York City.

When one of the light-colored aphids, like Myzus persice Sulz., is mounted alive on a depression slide, a rapid beating motion can be detected with the low power of the microscope in the tibia of each leg just below its juncture with the femur. These centers of activity mark the position of the pulsatile vessels.

The structure of these minute and delicate organs in aphids is difficult to determine, but serial sections through the tibia show that they are undoubtedly tubular. In the large aquatic Hemiptera, where they were first studied, the structure is more easily seen. Berlese ${ }^{1}$ describes them as tubular organs crossed obliquely with numerous muscle bands and continuous with a non-pulsating part on either side.

The function of these organs is clearly one of blood propulsion. Locy, ${ }^{2}$ who studied them in the aquatic Hemiptera, was able to discern the direction of the blood currents in the immediate vicinity of the pulsatile vessels, one current moving inward, the other outward. In Myzus persice, upon which most of my observations

1 Gli Insetti, Milano, 1909, p. 764, fig. 953.

2 American Naturalist, Vol. 18, pp. 13-19, 1884 (1 pl.). 
were made, the pulsations were rapid and irregular and for that reason difficult to count. A few attempts to determine the number per minute gave the following results: $150,124,176,51$. These must be taken as estimates only. Sometimes the pulsations would cease entirely in one leg for a number of seconds while continuing at the usual rate in the others. The periods of inactivity did not seem to be due to external stimuli. They occurred when the aphids were immersed in water or when placed on a dry depression slide. The movement of the dorsal heart was slower and of an entirely independent rhythm than that of the vessels.

Pulsations were observed in the very youngest aphids found. But no action was detected in large embryos, even those with the leg muscles and external spines well developed. Apparently the vessels are not functional till birth.

Locy has described the remarkable tenacity of these organs in the legs of Ranatra. In one case the vessel pulsated in an amputated leg for a period of 26 hours and 20 minutes. Activity continued even when sliced portions of the legs were used and when the vessel itself was cut in two, the posterior part still continued to pulsate. In contradistinction to this, the pulsatile vessels in the legs of Myzus persicce ceased beating (except for a few sporadic twitchings) immediately upon the removal of the legs. They would not resume their activity when the legs were quickly placed in water or physiological salt solution. If the head were cut off or burned off with a hot needle, the pulsations stopped at once. Aphids which were immersed in an aqueous solution of nicotine sulphate ( 1 part of 40 per cent. nicotine sulphate by volume to 500 parts of water), soon died and an immediate examination showed that the vessels in each leg had ceased to function. An injury from which the aphid finally partly recovered, such as a slight cut in the head, at first inhibited the action of the vessels, but with the recovery of the aphid, the vessels again resumed their normal rate of pulsation.

From the above results, it is evident that there is a marked difference in the reactions of the pulsatile vessels in Ranatra and Myzus persicee under certain abnormal conditions. Accepting Ranatra as the more generalized type, we notice a radical change in the resistance of the pulsatile vessels to various kinds of injury as we pass directly from this to the more highly specialized aphid 
type. An analogous case is found in the vertebrates in which the excised heart of such a comparatively generalized type as the frog is much more resistant than the heart of a specialized mammalian type like the dog, the cat, or man.

There is every reason to think that pulsatile vessels will be found in most, if not all, families and genera of the Hemiptera and Homoptera. Their discovery in the Aphididæ simply adds to the already convincing evidence of the close relationship of these two groups.

\section{ASCOGASTER CARPOCAPSE, A PARASITE OF THE ORIENTAL MOTH.}

By A. M. Wilcox,

Gipsy-moth Assistant, U. S. Bureau of Entomology.

The Oriental moth, Cnidocampa flavescens Walk., a native of Japan was first discovered in this country in 1906. Although at present the infestation is confined to a small area, there is a possibility of the moth becoming a widespread pest.

Several attempts have been made to rear parasites from the larvæ and cocoons of the moth, but as far as the writer knows, none of these previous attempts have been successful. During the spring of 1917 several of the cocoons were collected in Dorchester, Mass., and placed in rearing boxes. During the month of June the adults began to appear and a single Braconid parasite emerged at the same time. The specimen was determined by Prof. C. T. Brues of the Bussey Institution, Harvard University, as Ascogaster carpocapsoe Viereck. The species was first described as Chelonus carpocapsoe in 1909 by Viereck. ${ }^{1}$ The Codling moth, Carpocapse pomonella was named as the host insect.

The species may be recognized by the absence of segmentation on the abdomen and by the presence of four transverse nipple-like prolongations on the outer and upper edge of the posterior face of the metathorax. It can readily be separated from Chelonus fissus Prov., a common, similar species, by the absence of pubescence on the eyes, and the different wing venation, the first submarginal and first discoidal cells being separated in $A$. carpocapse, while in $C$. fissus they are confluent.

${ }^{1}$ Proc. Ent. Soc. Washington, Vol. 11, p. 43. 

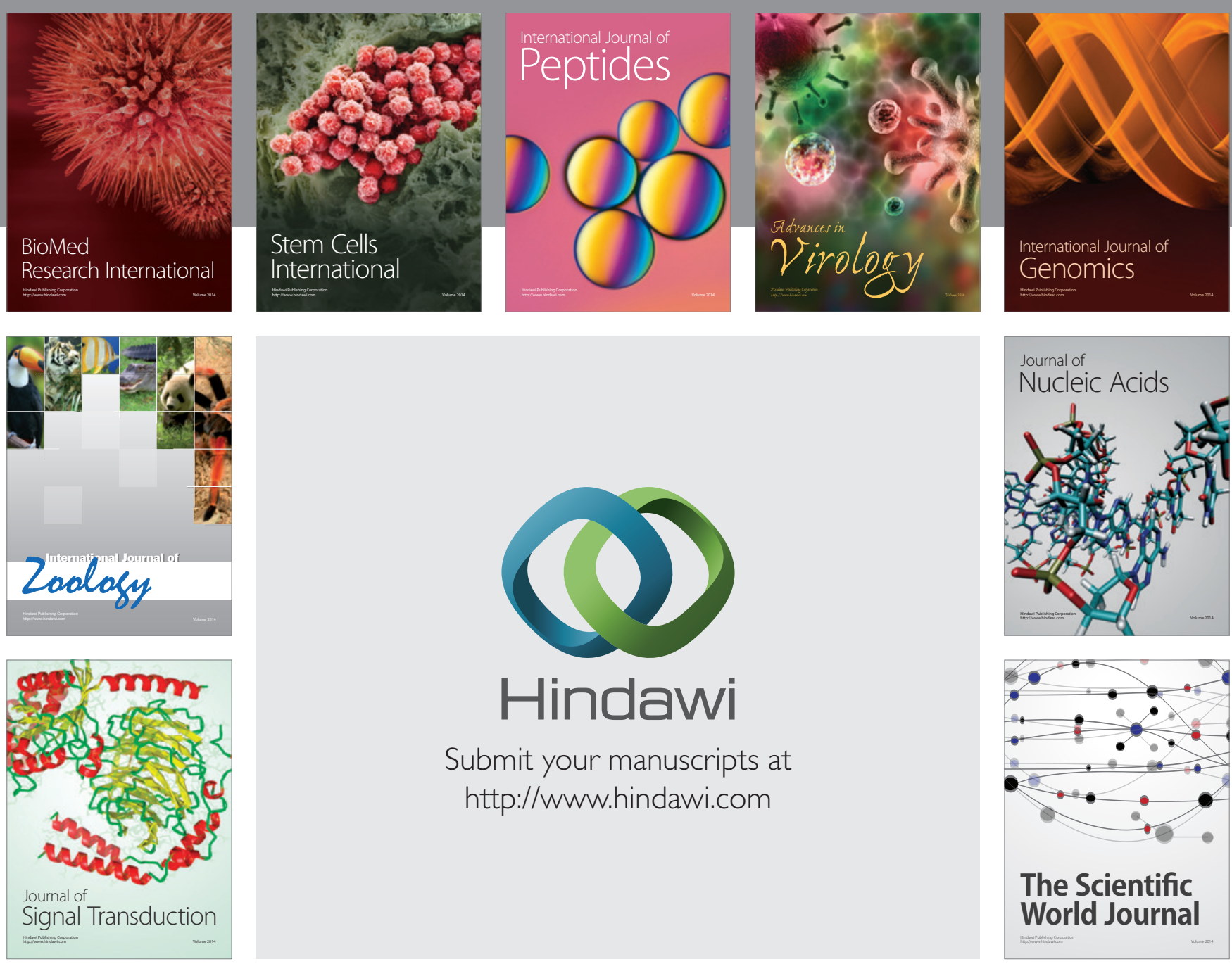

Submit your manuscripts at

http://www.hindawi.com
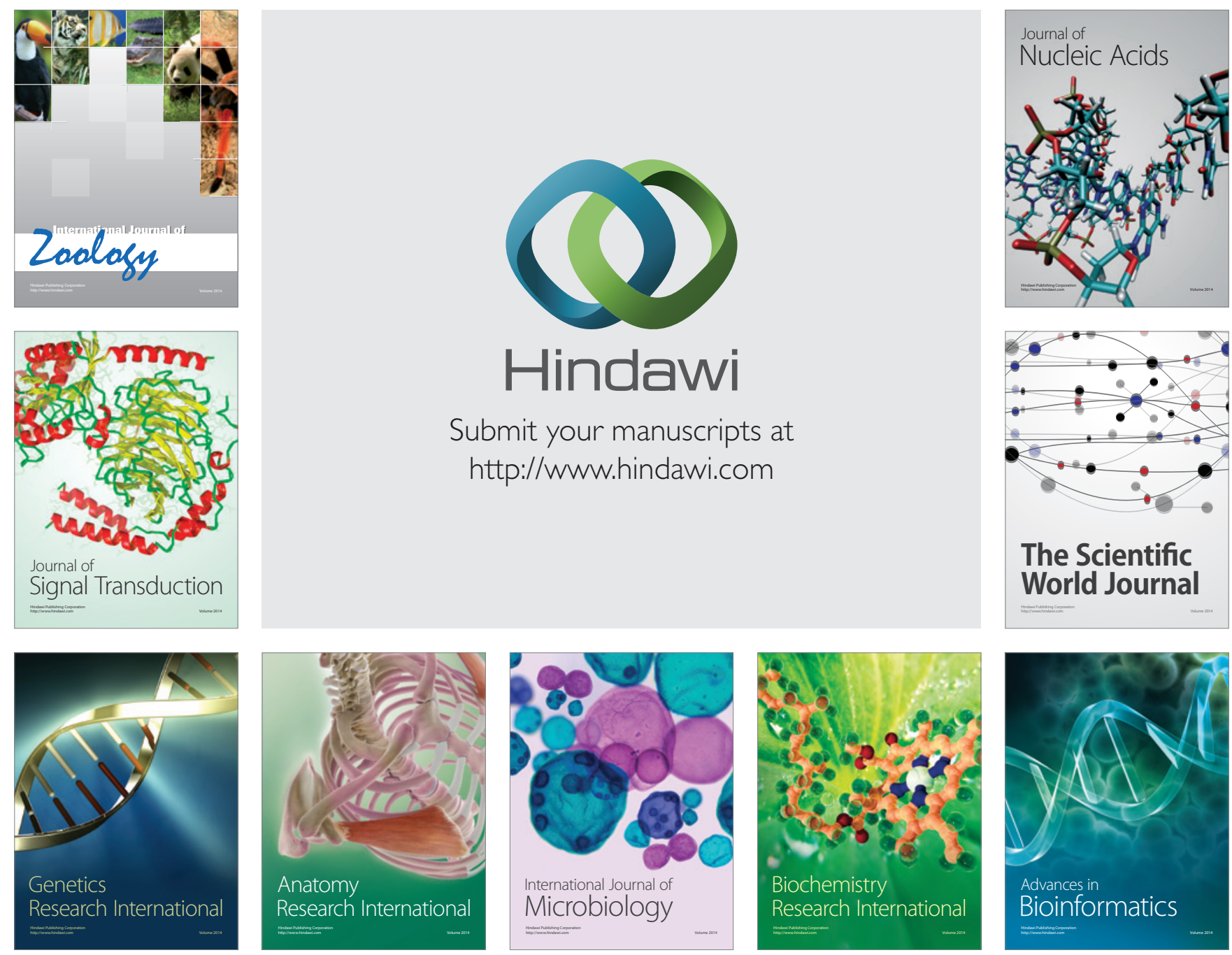

The Scientific World Journal
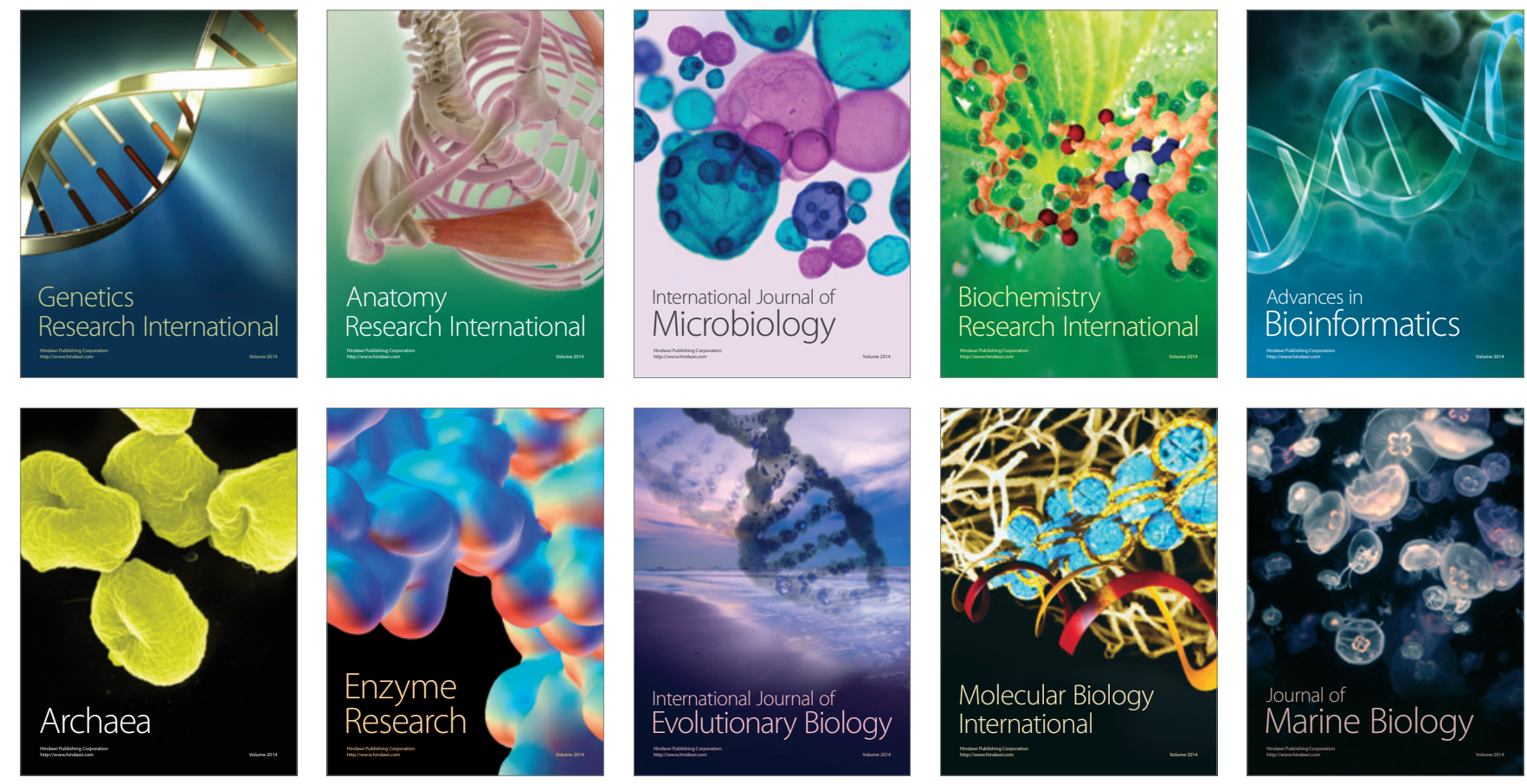